ASEAN Journal of Chemical Engineering 2021, Vol. 21, No. 2, 170 - 177

\title{
ErianthusPlant: A Rich Silica Source for Extraction of Amorphous Silica
}

Thet Mya Mya Sein*

\section{Ei Mon Aung}

Department of Chemical Engineering, Mandalay Technological University, Mandalay, Myanmar *e-mail: thetmyamyasein83@gmail.com, thetmyamyasein@mtu.edu.mm

Abstract. In this paper, Erianthus plant, a grass type of lignocellulosic biomass, is presented as an alternative source for the production of amorphous silica. Thermal treatment (combustion) of Erianthus plant under a controlled temperature of $600-900^{\circ} \mathrm{C}$ produces Erianthus Ash (EA). Then, silica powder was extracted from EA by the chemical extraction method. In this work, the effect of treatment temperature on the preparation of EA and extracted silica is studied. The EA samples and extracted silica are noted as EA600 - EA900 and Si600 - Sigoo respectively with respect to the treatment temperature. To evaluate the effect of the concentration of $\mathrm{NaOH}$ solution on the purity of silica, $\mathrm{NaOH}$ solution $(2-3 \mathrm{~N})$ is verified in this work. The results revealed that the pure amorphous silica can be extracted using a $2.5 \mathrm{~N} \mathrm{NaOH}$ solution from EA 800 . The percentage of amorphous silica with a purity of about $99 \%$ was confirmed by X-Ray Fluorescence (XRF).

Keywords: Ash, Erianthus, Extraction, Silica, Sodium Silicate.

\section{INTRODUCTION}

Erianthus plant, a grass type of lignocellulosic biomass, belongs to the tribe Andropogoneae under the grass family Gramineae (Amalraj et al. 2008). It belongs to the wild relative of sugarcane (Aitken et al. 2007) and can be used in the sugarcane breeding program due to its excellent biological traits and genetic relatedness to the sugarcane (Wang et al. 2019). As a warmseason species, it is better to grow under unfavorable environmental conditions such as submerged conditions and acidic soil, as well as under soil drought during the dry season. In Southeastern Asia, including Myanmar, Erianthus plant can be grown in subtropical and tropical regions ( $\mathrm{Hu}$ et al. 2017). In Myanmar, Erianthus plant is well known as giant grass as well as bushes or useless plant.

Erianthus plant is composed of cellulose, hemicellulose, and lignin (Yamamura et al. 2013) and thus, it is receiving much attention as an energy crop, a lignocellulosic biomass resource, for the production of biofuel (Hattori and Morita 2010, Ra et al. 2012, Dao et al. 2013, Hu et al. 2017). On the other hand, Yamamura et al. reported that Erianthus plant is rich in silica sources and they found that the percent of silica contained even in the leaf ash is more than $60 \%$ (Yamamura et al. 2013). However, to the best of our knowledge, no study has investigated the production of silica powder from Erianthus plant. Thus, this paper is attempted to produce amorphous silica from the Erianthus plant.

In Myanmar, the utilization of Erianthus 
plant is limited and it has not been successfully utilized in industries. Therefore, it results in tremendous waste generation and environmental pollution. Therefore, the plant will gain an additional value whether it can be used as a raw material for the production of a silica-based compound. Furthermore, it can be presented a novel utilization area for the efficient evaluation of this type of waste.

To investigate the experimental conditions for the production of amorphous silica from the Erianthus plant, thermal treatment prior to the chemical extraction method is referred from previous researches which investigated the extraction of silica from Rice Husk Ash (RHA) (Yuvakkumar et al. 2014, Rangaraj and Venkatachalam 2017). In this study, the thermal treatment temperature is considered at $600-900^{\circ} \mathrm{C}$ for 2 hr. In the chemical extraction method, the alkali extraction process is conducted followed by the acid precipitation method to produce amorphous silica. The effect of $\mathrm{NaOH}$ solution on the purity of produced silica is also investigated. The structural features of the extracted silica were thoroughly characterized by various techniques such as X-Ray Fluorescence (XRF), $X$-Ray Diffraction (XRD), Fourier Transforms Infrared (FT-IR), Scanning Electron Microscopy (SEM), and Energy Dispersive Spectroscopy (EDS) analysis.

\section{MATERIALS and METHODS}

\section{Raw Materials Preparation}

Raw Erianthus plant was collected from Thanlyin Township in Yangon Region, Myanmar in the winter season. The plants were washed with water to remove dirt and other contaminants. Then, the plants were sun-dried for one day and cut into small pieces. The pieces were dried again in an oven to remove moisture. The dried pieces were characterized by XRF to observe the composition.

\section{Thermal Treatment Process}

Erianthus Ash (EA) was produced by thermal treatment (combustion) of raw Erianthus plant under certain controlled temperature and time. Thermal treatment was performed in a muffle furnace at 600$900^{\circ} \mathrm{C}$ for $2 \mathrm{hr}$ with a heating rate of $20^{\circ} \mathrm{C} / \mathrm{min}$. The samples which are noted as $E_{600}-E_{900}$ were stored in a desiccator after the thermal treatment process. And then, the EA samples were characterized by XRF to determine the amount of silica content in percent.

\section{Extraction of Silica from EA}

The extraction experiment was referred to by the previous work (Yuvakkumar et al. 2014, Rangaraj and Venkatachalam 2017). The EA collected after combustion was leached with $100 \mathrm{ml}$ of $6 \mathrm{~N}$ hydrochloric acid solution under stirring at $70^{\circ} \mathrm{C}$ for $1.5 \mathrm{hr}$. Then, the acid-leached EA was filtered and washed with distilled water until the filtrate became neutral. After washing, EA was dried in an oven at $105^{\circ} \mathrm{C}$ for $24 \mathrm{hr}$ to remove water. In the extraction process, EA was refluxed with sodium hydroxide solution $(2-3 \mathrm{~N})$ under stirring for $2 \mathrm{hr}$ at $80^{\circ} \mathrm{C}$ to obtain sodium silicate solution. Then, this solution was filtered to extract the pure silica and remove impurities. Sodium silicate solution was precipitated by acidification process using $5 \mathrm{~N}$ sulfuric acid solutions. At this time, sodium silicate solution was accomplished under constant stirring at the controlled condition which the temperature is around $80 \pm 5^{\circ} \mathrm{C}$ for $1 \mathrm{hr}$. Finally, silica gel was formed by dropping sulfuric acid solution until $\mathrm{pH}$ level reaches $8 \pm 0.5$. The precipitated silica 
(silica gel) was washed repeatedly with distilled water until the filtrate become completely free alkali. The clean silica gel was dried in an oven at $100 \pm 5^{\circ} \mathrm{C}$ for $12 \mathrm{hr}$ to remove water. Finally, the pure silica powder was obtained after calcination in a muffle furnace at $450^{\circ} \mathrm{C}$ for $2 \mathrm{hr}$. The extracted silica samples were noted as Si600 - Sigoo with respect to combustion temperature.

\section{RESULTS AND DISCUSSION}

\section{Characterization of Raw Erianthus Plant}

Table 1. Chemical Composition of Raw Erianthus Plant

\begin{tabular}{cc}
\hline Component & Percent (wt \%) \\
\hline $\mathrm{SiO}_{2}$ & 43.29 \\
\hline $\mathrm{K}_{2} \mathrm{O}$ & 27.44 \\
\hline $\mathrm{SO}_{3}$ & 13.58 \\
\hline $\mathrm{CaO}$ & 8.30 \\
\hline $\mathrm{P}_{2} \mathrm{O}_{5}$ & 5.35 \\
\hline $\mathrm{Rb}_{2} \mathrm{O}$ & 0.02 \\
\hline $\mathrm{Fe}_{2} \mathrm{O}_{3}$ & 1.16 \\
\hline $\mathrm{MnO}_{2}$ & 0.41 \\
\hline $\mathrm{ZnO}$ & 0.08 \\
\hline $\mathrm{SrO}$ & 0.01 \\
\hline $\mathrm{CuO}$ & 0.15 \\
\hline $\mathrm{Cr}_{2} \mathrm{O}_{3}$ & 0.11 \\
\hline $\mathrm{PbO}$ & 0.06 \\
\hline $\mathrm{Ag}_{2} \mathrm{O}$ & 0.04 \\
\hline
\end{tabular}

To examine the content of silica in the raw Erianthus plant, its chemical composition was characterized by XRF as shown in Table 1. It was found that the plant is mainly composed of silica, $\mathrm{SiO}_{2}$, which has an amount of $43 \%$. Other metallic impurities are also present in Erianthus plant as minor elements. Potassium oxide $\left(\mathrm{K}_{2} \mathrm{O}\right)$ is noted as the major impurities.
Table 2. Chemical Composition of EA at Various Temperature

\begin{tabular}{|c|c|c|c|c|c|}
\hline 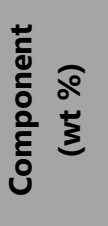 & 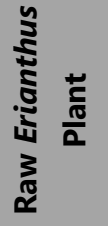 & 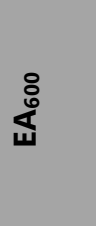 & 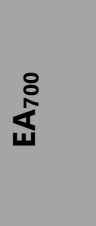 & 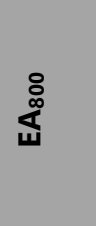 & 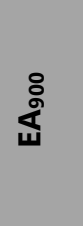 \\
\hline $\mathrm{SiO}_{2}$ & 43.29 & 53.6 & 58.1 & 68.0 & 64.82 \\
\hline $\mathrm{MgO}$ & NA & NA & NA & NA & 9.97 \\
\hline $\mathrm{K}_{2} \mathrm{O}$ & 27.44 & 20.95 & 18.31 & 12.37 & 8.52 \\
\hline $\mathrm{SO}_{3}$ & 13.58 & 9.84 & 9.80 & 5.96 & 4.98 \\
\hline $\mathrm{P}_{2} \mathrm{O}_{5}$ & 5.35 & 5.48 & 4.88 & 6.51 & 5.78 \\
\hline $\mathrm{CaO}$ & 8.30 & 5.72 & 5.42 & 6.28 & 5.12 \\
\hline $\mathrm{Cl}$ & NA & 3.85 & 2.89 & NA & NA \\
\hline $\mathrm{CuO}$ & 0.15 & 0.02 & 0.02 & 0.02 & 0.01 \\
\hline $\mathrm{TiO}_{2}$ & NA & 0.02 & 0.02 & 0.03 & 0.02 \\
\hline $\mathrm{Fe}_{2} \mathrm{O}_{3}$ & 1.16 & 0.23 & 0.28 & 0.48 & 0.37 \\
\hline $\mathrm{MnO}$ & 0.41 & 0.19 & 0.21 & 0.28 & 0.33 \\
\hline $\mathrm{ZnO}$ & 0.08 & 0.03 & 0.02 & 0.02 & 0.03 \\
\hline $\mathrm{SrO}$ & 0.01 & 0.02 & 0.02 & 0.03 & 0.03 \\
\hline $\mathrm{Rb}_{2} \mathrm{O}$ & 0.02 & 0.02 & 0.02 & 0.01 & 0.01 \\
\hline $\mathrm{Cr}_{2} \mathrm{O}_{3}$ & 0.11 & 0.01 & NA & 0.01 & 0.01 \\
\hline $\mathrm{Br}$ & NA & 0.01 & 0.01 & NA & NA \\
\hline$A c$ & NA & 0.01 & NA & NA & NA \\
\hline $\mathrm{PbO}$ & 0.06 & NA & NA & NA & NA \\
\hline $\mathrm{Ag}_{2} \mathrm{O}$ & 0.04 & NA & NA & NA & NA \\
\hline
\end{tabular}

NA - Not Available

\section{Effect of Temperature on Thermal Treatment Process}

The chemical composition of EA600 EA900 is shown in Table 2. It was obvious that $\mathrm{SiO}_{2}$ percent in ash samples after thermal treatment were increased when compared to that in the raw Erianthus plant.

It can be seen that percent $\mathrm{SiO}_{2}$ in $\mathrm{EA}$ samples is slightly increased up to $68 \%$ at $800^{\circ} \mathrm{C}$ while it was decreased to $64 \%$ at $900^{\circ} \mathrm{C}$. This might be due to the dissociation of potassium at this combustion temperature of $900^{\circ} \mathrm{C}$. At high combustion temperature, the surface of ash particles begins to melt and potassium can block the transportation of carbon dioxide and oxygen which can cause the increasing amount of unburnt carbon 
(Ugheoke and Mamat 2012). The present study discussed that the thermal treatment process affected the percent composition of $\mathrm{SiO}_{2}$ in EA samples. Therefore, the suitable burning temperature for the production of EA is $800^{\circ} \mathrm{C}$ for this study.

\section{Effect of Thermal Treatment Temperature on Extracted Silica}

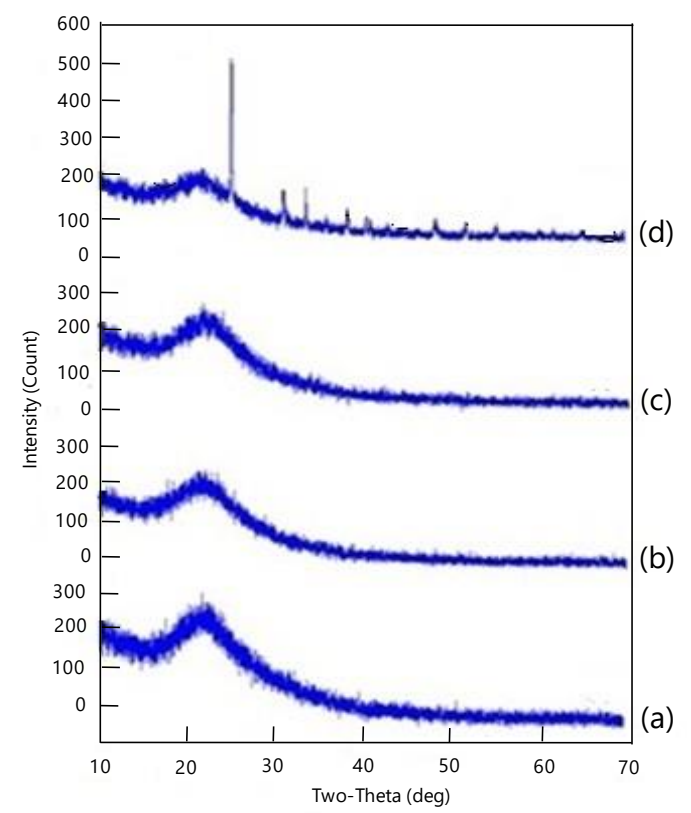

Fig. 1: XRD patterns of extracted silica (a) $\mathrm{Si}_{600}$ (b) Si700 (c) Si 800 (d) Sig00

The phase formation (amorphous or crystalline) of extracted silica was determined by XRD as shown in Figure 1. The broad diffused peaks with maximum intensity at $2 \theta$ $=22^{\circ}$ are observed in Si600 - Si 800 , indicating the amorphous nature of silica. However, the presence of a sharp peak at $2 \theta=25^{\circ}$ was observed in Sigoo. This indicates that the phase of extracted silica transformed to crystallization state at $900^{\circ} \mathrm{C}$. The results of the present study agreed with the previous researches which used RHA as raw materials for the extraction of silica (Deshmukh et al. 2012, Bakar, Yahya, \& Gan 2016). The researchers reported that the phase of RHA- derived silica is sensitive to the combustion temperature. Similarly, this study also confirmed that thermal treatment temperature affected the phase of the extracted silica. In contrast, thermal treatment temperature, over $800^{\circ} \mathrm{C}$, is not suitable to produce amorphous silica from the Erianthus plant.

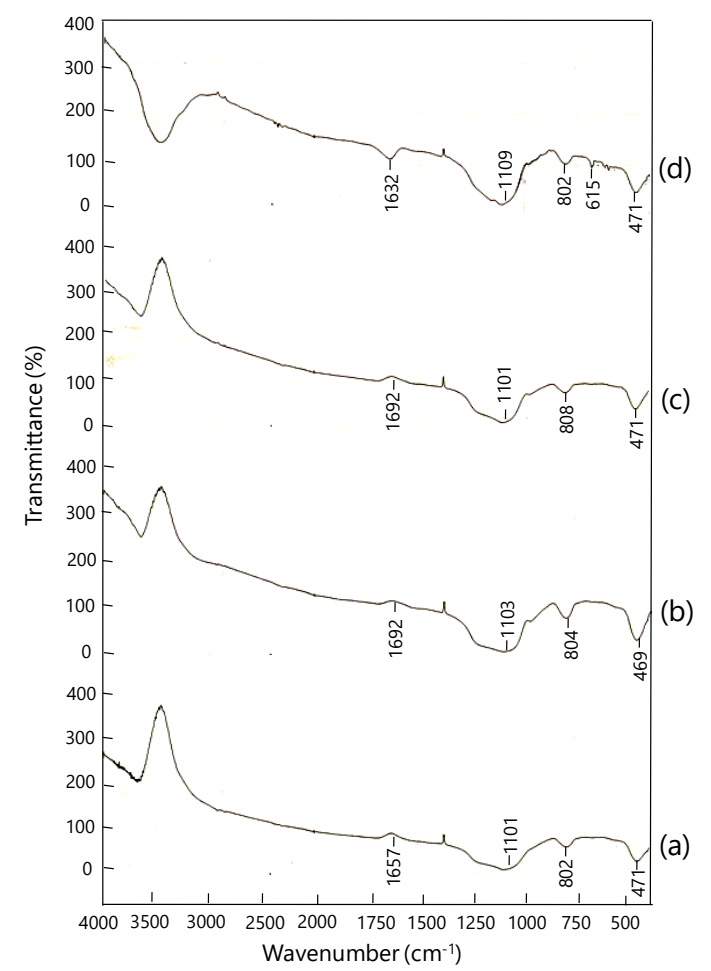

Fig. 2: FT-IR spectra of extracted silica (a) $\mathrm{Si}_{600}$ (b) Si $\mathrm{S}_{700}$ (c) Si 800 (d) Sig00

FT-IR spectra of extracted silica, Si600 Sigoo, are shown in Figure 2. The IR band at around $471 \mathrm{~cm}^{-1}$ belongs to bending vibrations of $\mathrm{O}-\mathrm{Si}-\mathrm{O}$ groups. The strong band around $808 \mathrm{~cm}^{-1}$ and $1109 \mathrm{~cm}^{-1}$ reveal the existence of $\mathrm{Si}-\mathrm{O}-\mathrm{Si}$ symmetric and asymmetric stretching vibrations. The regions around $1692 \mathrm{~cm}^{-1}$ assigned to the absorption band for $\mathrm{H}-\mathrm{O}-\mathrm{H}$ bending vibration in water (Amutha, Ravibaskar, and Sivakumar 2010, Musić, Filipović-Vinceković, and Sekovanić 2011). 


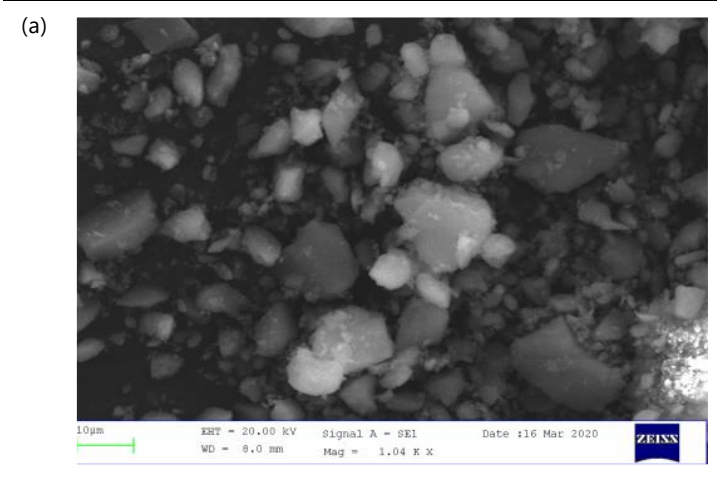

(b)

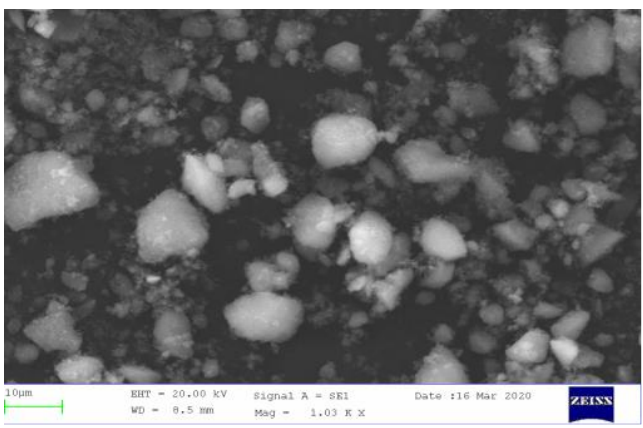

(c)

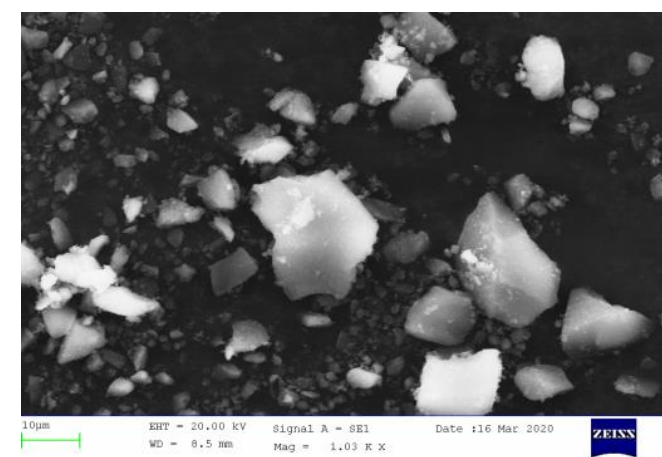

(d)

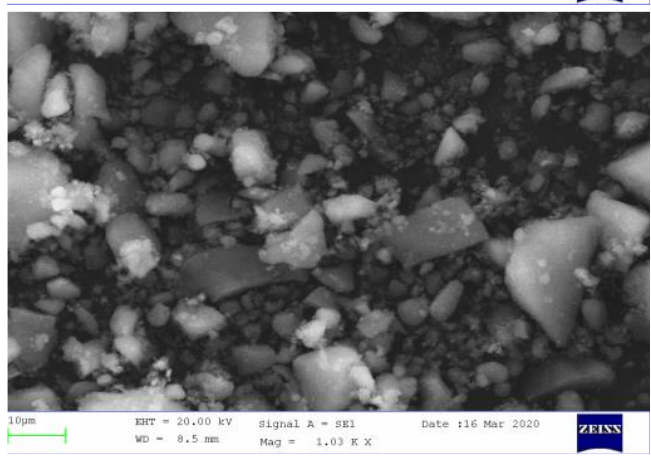

Fig. 3: SEM analysis of extracted silica (a)

$$
\mathrm{Si}_{600} \text { (b) Si700 (c) Si } 800 \text { (d) Sig00 }
$$

Thus, FT-IR spectra of all extracted silica, Si600 - Sigoo, indicate the major functional groups of silica. Notably, the band at around $615 \mathrm{~cm}^{-1}$ might correspond to cristobalite $\mathrm{SiO}_{2}$ in Sigoo (An et al. 2011, Azmi et al. 2016). This fact correlates with XRD analysis which indicates that the phase of silica transformed to cristobalite form at thermal treatment temperature, $900^{\circ} \mathrm{C}$. This implies that thermal treatment temperature is affected by the phase of the extracted silica.

SEM images of extracted silica are shown in Figure 3. It was observed that the shape of silica particles of all samples, Si600 - Sigoo, was irregular morphology with agglomeration. The size of particles was displayed approximately about $10 \mu \mathrm{m}$. According to the SEM results, it can be suggested that thermal treatment temperature does not affect the morphology of the extracted silica in this study.

\section{Effect of $\mathrm{NaOH}$ Solution Concentration on Purity of Silica}

The chemical composition of the extracted silica was determined by XRF and the results are shown in Table 3.

Table 3. Composition of Silica Extracted

\begin{tabular}{cccc}
\hline $\begin{array}{c}\text { Component } \\
\text { (wt \%) }\end{array}$ & $\mathbf{2 ~ N}$ & $\mathbf{2 . 5} \mathbf{~ N}$ & $\mathbf{3} \mathbf{~ N}$ \\
\hline $\mathrm{SiO}_{2}$ & 97.27 & 99.00 & 98.34 \\
\hline $\mathrm{K}_{2} \mathrm{O}$ & 0.04 & $\mathrm{NA}$ & 0.30 \\
\hline $\mathrm{SO}_{3}$ & 0.63 & 0.60 & 0.04 \\
\hline $\mathrm{CuO}$ & 0.50 & 0.03 & 0.01 \\
\hline $\mathrm{TiO}_{2}$ & 0.03 & 0.02 & 0.31 \\
\hline $\mathrm{Fe}_{2} \mathrm{O}_{3}$ & 0.70 & 0.17 & 0.20 \\
\hline $\mathrm{MnO}_{\mathrm{ZnO}}$ & 0.01 & 0.04 & 0.10 \\
\hline $\mathrm{ZnO}$ & 0.17 & 0.03 & 0.20 \\
\hline $\mathrm{ZrO}_{2}$ & 0.02 & $\mathrm{NA}$ & 0.10 \\
\hline $\mathrm{CaO}_{2}$ & 0.60 & 0.10 & 0.10 \\
\hline $\mathrm{Rb}_{2} \mathrm{O}$ & 0.01 & $\mathrm{NA}$ & 0.10 \\
\hline $\mathrm{Cr}_{2} \mathrm{O}_{3}$ & 0.02 & 0.01 & 0.20 \\
\hline
\end{tabular}

NA - Not Available

It was observed that the purity of extracted silica with $2.5 \mathrm{~N} \mathrm{NaOH}$ solution has confirmed the highest silica content, 99\%. Notably, $\mathrm{K}_{2} \mathrm{O}$ which is the main metallic 
impurities could be removed at this condition. Thus, the results reveal that $\mathrm{NaOH}$ solution concentration has the effectiveness of the purity of silica. This result bears a resemblance to the investigation on production of silica from RHA reported by Yuvakkumar et al. They investigated that $\mathrm{NaOH}$ affects the production of high purity nano-silica powder from RHA (Yuvakkumar et al. 2014).

(a)

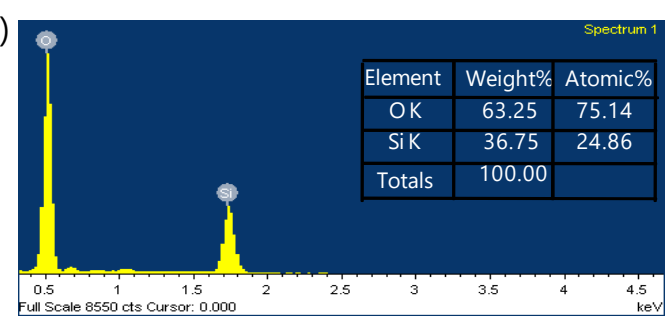

(b)

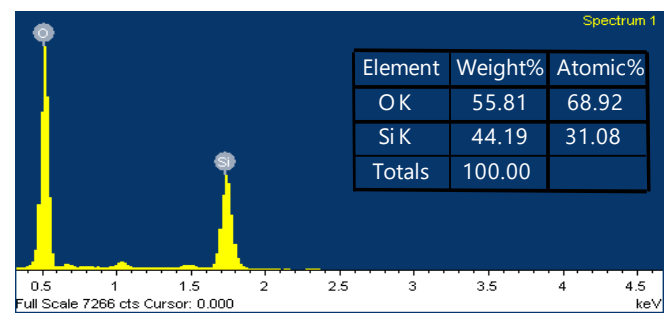

(c)

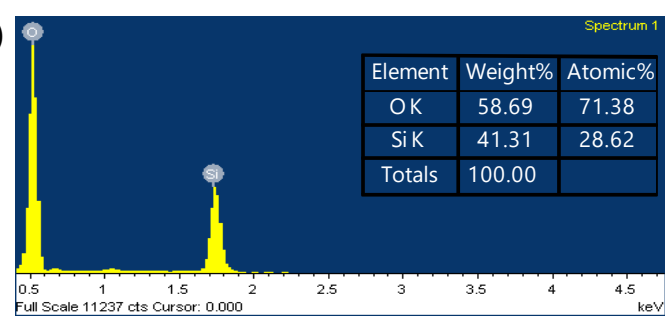

Fig. 4: EDS pattern of extracted silica powder with various $\mathrm{NaOH}$ solution (a) $2 \mathrm{~N}$ $\mathrm{NaOH}$ (b) $2.5 \mathrm{~N} \mathrm{NaOH}$ and (c) $3 \mathrm{~N} \mathrm{NaOH}$

The EDS patterns described in Figure 4 also confirmed that extracted silica samples predominantly contain elements such as $\mathrm{Si}$ and $\mathrm{O}$ as the results indicate the absence of other elements such as $\mathrm{K}$ and $\mathrm{C}$. Hence, the results confirm the formation of pure silica structures. Notably, the silica sample extracted with $2.5 \mathrm{NaOH}$ solution contains 44.19 wt\% silicon and 55.81 wt\% oxygen while the actual composition of silicon in silica is 46 wt\% (Yuvakkumar et al. 2014). From the EDS results, it can be confirmed that the silica sample extracted with $2.5 \mathrm{~N} \mathrm{NaOH}$ solution contains higher purity of silica, $97 \%$ than the two others. Since the other samples extracted with $2 \mathrm{~N}$ and $3 \mathrm{~N} \mathrm{NaOH}$ solution contain $80 \%$ and $90 \%$ purity of silica respectively. Thus, the EDS results also confirm the effectiveness of the concentration of $\mathrm{NaOH}$ solution, and $2.5 \mathrm{~N}$ is noted as an optimum condition to extract the high purity of silica.

The yield of silica extracted from ash at various temperatures with $2.5 \mathrm{~N} \mathrm{NaOH}$ solution is shown in Table 4.

Table 4. Yield of Silica at Various

Temperature with $2.5 \mathrm{~N} \mathrm{NaOH}$ Solution

\begin{tabular}{cc}
\hline Sample & Yield (\%) \\
\hline Si 600 & 74 \\
Si $_{700}$ & 75 \\
\hline Si 800 & 77 \\
\hline Si 900 & 70 \\
\hline
\end{tabular}

\section{CONCLUSIONS}

This work is contributed to the optimization of experimental conditions for the production of amorphous silica from Erianthus plant. In this study, Erianthus plant was thermally treated at $600-900^{\circ} \mathrm{C}$ to produce EA and then chemical extraction of EA was conducted to produce amorphous silica. It appears that the production of amorphous silica from Erianthus plant can be effective. The combustion temperature for the production of EA is also studied and it was found that the EA produced at the temperature of $800^{\circ} \mathrm{C}$ for $2 \mathrm{hr}$ duration time is the optimum condition in terms of 
amorphous silica. The effect of $\mathrm{NaOH}$ solution on the extraction of silica is demonstrated. It was observed that $2.5 \mathrm{~N}$ $\mathrm{NaOH}$ solution can be produced high purity amorphous silica, 99\% from EA800 in this study.

\section{ACKNOWLEDGEMENT}

The authors are grateful to acknowledge the persons from Department of Chemical Engineering, Mandalay Technological University for their valuable suggestions and help.

\section{REFERENCES}

1. Aitken, K., Li, J., Wang, L., Qing, C., Fan, Y. H., \& Jackson, P., (2007), "Characterization of intergeneric hybrids of Erianthus rockii and Saccharum using molecular markers", Genet. Resour. Crop Evol., 54(7),13951405.

2. Amalraj, V. A., Rakkiyappan, P., Neelamathi, D., Chinnaraj, S., \& Subramanian, S., (2008), "Wild cane as a renewable source for fuel and fibre in the paper industry", Curr. Sci. 95, 1599-1602.

3. Amutha, K., Ravibaskar, R., \& Sivakumar, G., (2010), "Extraction, synthesis and characterization of nanosilica from rice husk ash", Int. J. Nanotechnol. Appl. 4, 61-66.

4. An, D., Guo, Y., Zou, B., Zhu, Y., \& Wang, Z., (2011), "A study on the consecutive preparation of silica powders and active carbon from rice husk ash", Biomass and Bioenergy 35, 1227-1234.

5. Azmi, M. A., Ismail, N. A. A., Rizamarhaiza, M., Hasif, A. A. K. W. M., \& Taib, H., (2016), "Characterisation of silica derived from rice husk (Muar, Johor, Malaysia) decomposition at different temperatures", In AIP Conf.
Proc. Vol. 1756.

6. Bakar, R. A., Yahya, R., \& Gan, S. N., (2016), "Production of High Purity Amorphous Silica from Rice Husk", Procedia Chem. 19, 189-195.

7. Dao, Z. X., Yan, G. J., Zhang, J. B., Chang, D., Bai, S. J., Chen, Z. H., Li, D. X., You, M. H., Zhang, Y., Zhang, C. B., Zhang, J., Yan, X., \& Hu, C., (2014), "Investigation and Collection of Wild Erianthus arundinaceum Germplasm Resources", J. Plant Genet. Resour. 14, 816-820.

8. Deshmukh, P., Bhatt, J., Peshwe, D., \& Pathak, S., (2012), "Determination of silica activity index and XRD, SEM and EDS studies of amorphous SiO 2 extracted from rice Husk Ash", Trans. Indian Inst. Met., 65,63-70.

9. Hattori, T., \& Morita, S., (2010), "Energy crops for sustainable bioethanol production; which, where and how?", Plant Prod. Sci. 13, 221234.

10. Hu, Y., Zhang, L., Hu, J., Zhang, J., Shen, F., Yang, G., Zhang, Y., Deng, S., Qi, H., Yan, J., \& Bai, S., (2017), "Assessments of Erianthus arundinaceus as a potential energy crop for bioethanol and biomethane production", BioResources 12, 87868802.

11. Musić, S., Filipović-Vinceković, N., \& Sekovanić, L., (2011), "Precipitation of amorphous $\mathrm{SiO} 2$ particles and their properties", Brazilian J. Chem. Eng. 28, 89-94.

12. Ra, K., Shiotsu, F., Abe, J., \& Morita, S., (2012), "Biomass yield and nitrogen use efficiency of cellulosic energy crops for ethanol production", Biomass Bioenerg., 37, 330-334.

13. Rangaraj, S., \& Venkatachalam, R., (2017), "A lucrative chemical processing of bamboo leaf biomass to synthesize biocompatible amorphous silica nanoparticles of biomedical importance", Appl. Nanosci. 7, 145-153. 
14. Ugheoke, I. B., \& Mamat, O., (2012), "A critical assessment and new research directions of rice husk silica processing methods and properties", Maejo Int. J. Sci. Technol., 6(3),430448.

15. Wang, W., Li, R., Wang, H., Qi, B., Jiang, X., Zhu, Q., Cai, D., Tang, X., \& Zhao, Q., (2019), "Sweetcane (Erianthus arundinaceus) as a native bioenergy crop with environmental remediation potential in southern China: A review", GCB Bioenergy 11, 10121025.

16. Yamamura, M., Noda, S., Hattori, T., Shino, A., Kikuchi, J., Takabe, K., Tagane, S., Gau, M., Uwatoko, N., Mii, M., Suzuki, S., Shibata, D., \& Umezawa, T., (2013), "Characterization of lignocellulose of Erianthus arundinaceus in relation to enzymatic saccharification efficiency", Plant Biotechnol. 30, 25-35.

17. Yuvakkumar, R., Elango, V., Rajendran, V., \& Kannan, N., (2014), "High-purity nano silica powder from rice husk using a simple chemical method", J. Exp. Nanosci. 9, 272-281. 